\title{
Healthier? More Efficient? Fairer? An Over- view of the Main Ethical Issues Raised by the Use of Ubicomp in the Workplace
}

\author{
Céline Ehrwein Nihan ${ }^{\mathrm{a}}$ \\ ${ }^{a}$ School of Business and Engineering Vaud, Av. des Sports 20, CH-1400 Yverdon-les-Bains, Switzerland, \\ celine.ehrwein@heig-vd.ch
}

KEYWORD

Intelligent Working Environ-
ment
Ambient Intelligence
Human Resources
Human Resource Manage-
ment
Ethics

\section{Introduction'}

The last decades have witnessed the rapid development of a whole series of researches in the field of "new technologies". This development has not only stirred many discussions in academic circles and the public space, but it has also led to the emergence of new disciplinary fields, particularly in the field of ethics. Alongside the "traditional" bioethics, today we can find a multitude of other ethical applied approaches such as nanoethics, the ethics of genetics, computer ethics, neuroethics, etc.

Technologies which have given rise to these new areas of ethical reflection tend more and more to appear merged. This phenomenon has led to what is often termed the "converging" technologies, or NBIC technologies (in reference to Nanotechnology, Bio-

${ }^{1}$ IWE = Intelligent Working Environment; HR = Human Resources; HRM = Human Resource Management technology, technology Information and Cognitive sciences).

The thus called "intelligent environments" 2 - on which we will focus in this article - are particularly representative of this phenomenon, as well as of the transformations that it implies. They presuppose an omnipresence of computer technology (ubiquitous computing), which is radically transforming our perception of reality and our relation to the world [FLORIDI, 2010].

Indeed, in recent years, several scholars have begun to focus on the ethical and social issues raised by the development of these intelligent environments [FLORIDI, 2010; TAVANI, 2011; BOHN et al., 2004; HILTY et al., 2003; HILTY et al., 2004]. Some of them have looked at the ability of the ambient intelligence to support therapeutic or medical activities

${ }^{2}$ Regarding the terminology see Daniel Ronzani, The Battle of Concepts: Ubiquitous Computing, Pervasive Computing and Ambient Intelligence in Mass Media, UbiCC Journal 4 (2) (2009), pp. 9-19. 
towards people with specific health problems (elderly people, diabetics, people with psychiatric disorders, etc.) [SCHUURMANN et al. 2009].

But the development of ubiquitous computing offers other opportunities. It might also be used by companies for managerial purposes. Intelligent environments might be integrated in the workplace to measure and improve working conditions, to check the employees' "state of functioning", to enhance their well-being and performance, and, of course, to optimize corporate productivity. If it is becoming a reality, this kind of use will have a considerable impact on the management and the ethics of HR.

However, we can now observe that the publications dedicated to the emergence of ambient intelligence in the workplace show little interest in these issues.

Most of the existing studies have so far put focus on technical difficulties related to the programming or the design of these new environments [ANISETTI et al., 2006; SOUSA, 2010]. Some address the question of the implications of ubiquitous computing for Information Technology Management in companies [PATTEN et al., 2005]; others have made studies on the acceptance of IWE [RÖCKER, 2009] while other studies have tried to sketch scenarios of the future workplace [BÜHLER, 2009]. The studies dedicated to the examination of the ethical and managerial issues of these developments are scarce. This gap is even more striking when we know that the first applications related to the workplace are making their appearance on the market at a brisk pace ${ }^{3}$.

\section{Objective, Outline and Method}

In this article, I would like to offer a first overview of the main ethical issues related to the development of IWEs and in particular to their capacity to collect and monitor data containing personal medical information such as our heart rate, brain activity or emotional state.

\footnotetext{
${ }^{3}$ See for example the 3D job interviews simulator developed by the Centre de réalité virtuelle de Clermont-Ferrand and the consulting company Athalia (www.aprv.eu) or the intelligent fireman hood developed by the firm Bodysens (www.bodysens.com).
}

In this perspective, I will first clarify the background of the current developments (3). To do so, I will briefly introduce a typology which should help us to categorize the different computing tools that have appeared in recent decades (3.1.). I will then move the focus on the thus called "intelligent environments". I will say a few words about their origins and their features that can be identified on the basis of an analysis of the existing literature (3.2.), before mentioning a few examples of applications, most of them related to working environments (3.3.). In the next section (4.), I will try to point out the main ethical issues raised by the ability of these environments to monitor data containing medical information. Following a consequentialist approach, I will begin to present a quick overview of the potential positive and negative impacts involved by this ability (4.1.). Then I will point out some more fundamental socio-ethical challenges raised by the development of these environments (4.2.). Finally, I will offer elements of reflection on ethical principles to the discussion that could help us to frame the potential negative impact of the upcoming development of ambient intelligence in the workplace (5).

\section{Theoretical background: what are we talking about?}

\subsection{Typology of the computing tools}

Following the work of authors like Kalle Lyytinen and Youngjin Yoo [LYYTINEN et al., 2002], we can order the developments realized over the last decades in the field of computer sciences on two lines (see Figure 1). The first line indicates the degree or level of mobility of the technological tool. The question here is to estimate to what extent and in what proportions the tool we use is mobile or not. The second line assesses its degree of integration or embeddedness in the workplace or, more specifically, its ability to monitor, record and handle data related to the environment in which it is integrated.

Thus, the first computers that appeared in our workplaces were not mobile - not to say irremovable. Besides they had no ability to measure and handle data related to their environment (1). Gradually, laptops, mobile phones and, more recently, the first smart phones - true small pocket computers that may 
be taken everywhere - have appeared on the market. These first mobile tools presented a relatively restricted, not to say non-existent, level of integration: their functions were essentially limited to word processing, calculation and spreadsheet, as well as to social communication (phone, e-mail) (2).

But, gradually, progresses were also made on the integration line. In recent years, numerous scholars have worked on the development of the computer's capacities to measure and handle ambient data (like the temperature, the luminosity, the tone of a voice, the presence of certain substance in the atmosphere, etc.). We have already used various applications of home automation as for example, blinds that automatically close when the solar radiations become too strong. Having said so, we must acknowledge that the potential integration of today computing tools goes far beyond this type of application. A large number of systems developed by ITC specialists are not following the binary impulse-reaction logic of traditional mechanics any more: they can measure, record and simultaneously analyze a wild range of data related to their environment and treat these in such a way in order to offer an innovative and tailored response to those who are in contact with them. A group of researchers of the Institute of Engineering of Porto, ISEP [RAMOS et al., 2010], for instance, has imagined a conference room which should be able to take into accounts the emotions and the arguments expressed by the participants of a meeting and use them to play an active role in discussions (3).

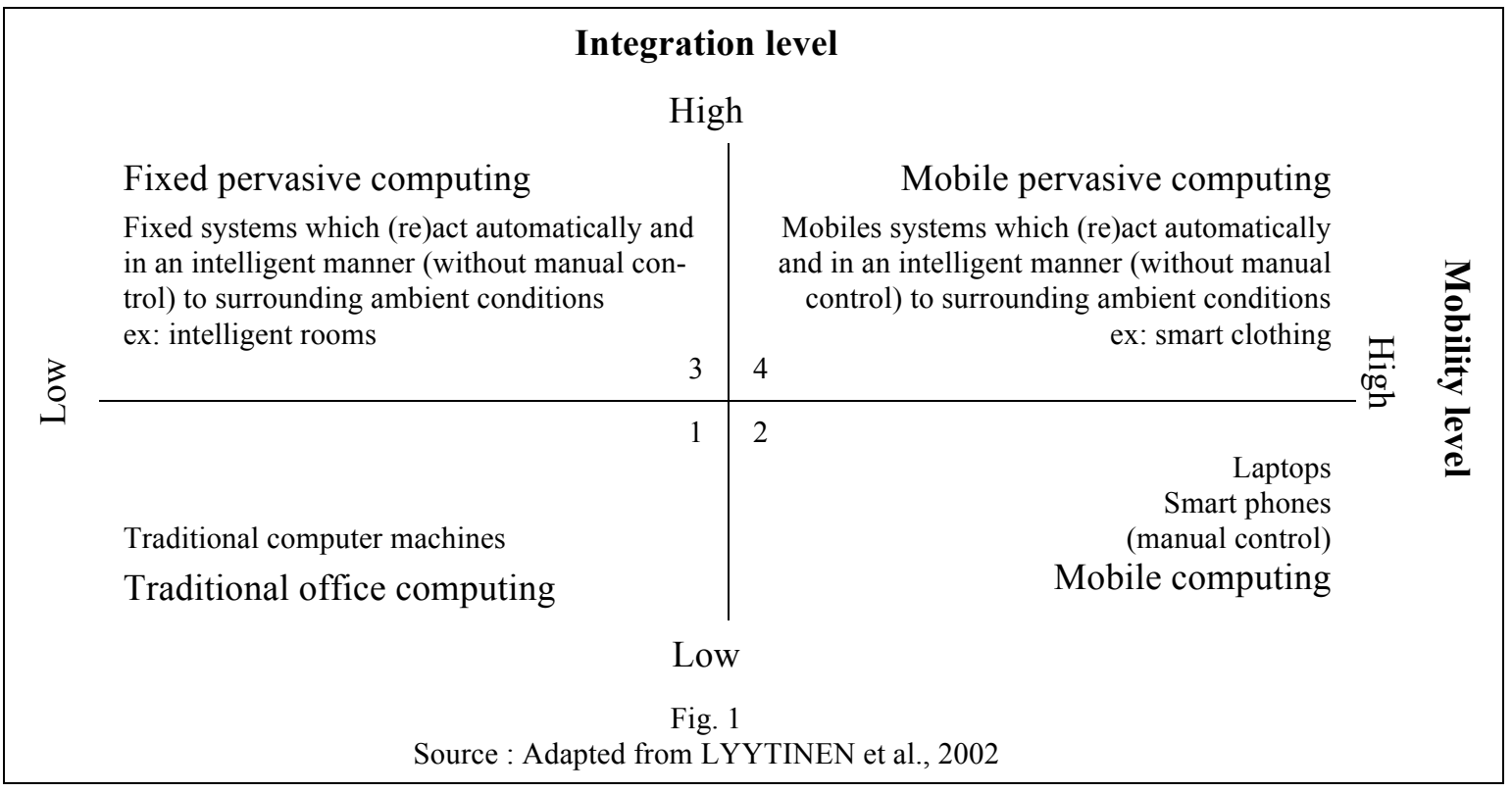

While some systems, like the one I have just mentioned, are limited to a given environment (a room, a natural location, etc.), others are much more mobile (4). The Swiss Center for Electronics and Microtechnology (CSEM) in Neuchâtel, for instance, has imagined a firefighter jacket, apparently normal, which can monitor the heart rate and the body temperature of the person who wears it, thanks to sensors integrated in the fabric. Mobile and perfectly embedded in its environment, this jacket should support firemen by allowing them to monitor in real time their level of stress as well as other health risks related to their job.

When we are speaking of ambient intelligence, ubiquitous computing, pervasive computing or intelligent environments ${ }^{4}$, we are essentially referring to these two latter types of technology $(3+4)$. Before trying to identify more closely the features of these tools, it might be useful to say a few words about their origins.

${ }^{4}$ Regarding the terminology see Daniel Ronzani, The Battle of Concepts: Ubiquitous Computing, Pervasive Computing and Ambient Intelligence in Mass Media, UbiCC Journal 4 (2) (2009), pp. 9-19. 


\subsection{The Origins of Ambient Intelli- gence and its Main Features}

It is current to attribute the paternity of the ambient intelligence to the American researcher Mark Weiser (1952-1999) who was Head of laboratory and then Chief Technologist at the Xerox Palo Alto Research Center (PARC) between 1987 and 1999 (Bohn et al. 2004; Kinder 2008). The basic idea was apparently to develop "wall-sized, flat panel computer displays [which could also] function as input devices for electronic pens" [WEISER et al., 1999]. Very quickly, a further idea was introduced, namely, that computers should be spread ubiquitously in the environment (floor, walls, etc.) and in the objects of our everyday life (furniture, clothes, accessories, etc.). Allowing computing to become ubiquitous, the researchers at PARC "wanted to put computing back in its place, to reposition it into the environment background, to concentrate on human-to-human interface and less on human-to-computer once. By 1992, when [their] first experimental 'ubi-comp' system was being implemented, [they] came to realize that [they] were, in fact, actually redefining the entire relationship of humans, work, and technology for the post PC-era" [WEISER et al., 1999, 694]

Ubiquity is not the only striking feature of ambient intelligence. Ambient intelligence is also characterized by invisibility or, more exactly, by its nonperceptibility. As Nijholt states it, the ambient intelligence does not only remove computers from our field of vision, but also provokes "the mental disappearance of the computing device" [NIJHOLT, 2004, 471].

Sensitivity is another important feature of ambient intelligence. Miniaturized biosensors enable computers to measure and communicate information to their environment. As I have already said, data collected and analyzed might be from various sources: chemi- cal, biological or physiological data, such as the temperature of a room, the presence of a particular substance in the atmosphere, one's electroencephalogram, one's facial expressions or emotional state [ALLANSON et al., 2004]. This capacity made scholars say that ambient intelligence is aware of its context (context awareness).

Like most of computing systems, the thus called "intelligent" environments have a large memory capacity. The latter are able, for instance, to record an extensive set of data in the long term, and spot on this basis variations which affect the pace and progress of work, as well as the performance, the level of fatigue and stress of workers.

That said, to be fully "intelligent", the computing tool must be able to adapt to its context and to the data it collects and analyses. It should have the capacity to react with regards to these data in a targeted and personalized manner, and respond to the particular needs of the persons who are in contact with it [STEFANI et al. 2007].

This adaptation skill combines with an anticipation skill. In other words, it is expected from the intelligent environments to meet the user's needs even before these needs appear.

Finally, ambient intelligence is often associated to, or even regarded as equivalent to the thus called "persuasive" technologies. Being able to anticipate the user's behaviour and to adapt itself to it, the computer becomes a powerful instrument of persuasion [van den BROEK et al., 2006; HOFKIRCHNER et al., 2007; KAPTEIN et al., 2010].

This assertion leads to the definition of IWEs. I base my own approach on the proposal made by the interdisciplinary research group "Intelligent Working Environments: Socio-ethical and Human Resource Management Challenges" of the School of Business and Engineering Vaud (HEIG-VD, Switzerland).

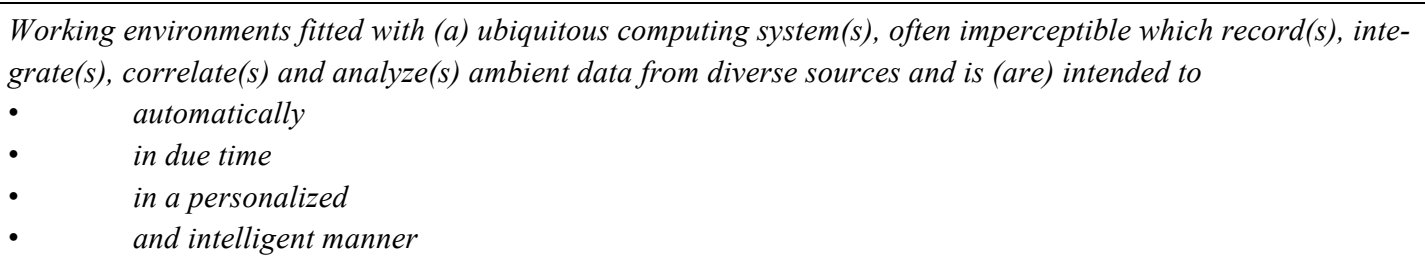

Fig. 2: Definition of Intelligent Working Environments Source : Groupe de recherche IWE \&HRM 2012 


\subsection{Application of Ambient Intelli- gence at work}

I would like to add other examples of application to those given in the foot note 3 and point 3.1. In the context of this paper, I will confine myself to a short enumeration of applications related to the workplace in order to allow everyone to obtain a better idea to what tomorrow work could look like. These are just a few examples that we may find in the literature dedicated to ICT:

- $\quad$ a system which dynamically, automatically and in an autonomous manner organizes the planning of a medical team, taking into account the possible emergency health care situations, etc. [CORCHADO et al., 2008];

- a personal digital assistant which can guide employees step by step in the accomplishment of the tasks they have to perform for the maintenance of machines and which offer the possibility of a distance video monitoring systems to deal with particular problems [BÜHLER, 2009];

a system which is able to detect the temporary memory loss of a worker, to remind him or her of the tasks that have been done and of those that still need being done, and, if necessary, to contact automatically a support person [BÜHLER, 2009];

a smart computer which is able to assess the fatigue of its user by measuring his/her blink rate and to react by "increasing font size or screen contrast in order to ease" reading [ALLANSON et al., 2004]; a computational interface which is capable of evaluating the level of frustration of a person by measuring his or her heart rate and blood pressure, and which, on this basis, may adapt itself to the user's needs [ALLANSON et al., 2004];

- $\quad$ etc.

\section{Results}

No need to say that the development of ambient intelligence raises important ethical issues. The context of this presentation does not allow me to examine these issues in detail. Nevertheless, I would like to point out those that I consider as the most important ones in order to provide an overview of the coming challenges and generate a debate. As stated, I will focus on the use that can be made of the IWEs to measure, record and monitor data containing personal medical information (physical or psychological).

\subsection{Risks and Opportunities of the Use of Intelligent Health Monitoring Systems in the Workplace}

In the two tables below, I have tried - on the basis of the studies which have been made so far - to briefly list the main advantages and disadvantages that may arise, on the individual, organizational and social levels, because of the use of the IWE's capacity to measure, record and monitor data containing personal medical information.

\begin{tabular}{|l|c|c|c|}
\hline \multicolumn{1}{|c|}{ Table 1: Opportunities and possible advantages for the... } & ind. & org. & soc. \\
\hline $\begin{array}{l}\text { Opportunity of a better adaptation of working places to the physical and mental abilities of } \\
\text { workers, as well as to their specific medical needs [BÜHLER, 2009]. }\end{array}$ & $\mathrm{x}$ & & \\
\hline $\begin{array}{l}\text { Opportunity of a better control and prevention of accidents at work (in case of accidents due } \\
\text { to medical disorders, such as for instance attention deficit disorder) }\end{array}$ & $\mathrm{x}$ & $\mathrm{x}$ & $\mathrm{x}$ \\
\hline $\begin{array}{l}\text { Opportunity of a better health control and protection for workers thanks to good anticipation, } \\
\text { early detection and personalized treatment of medical disorders (ex: early detection and } \\
\text { treatment of cardiac palpitations) [BÜHLER, 2009; Azteca Project] }\end{array}$ & $\mathrm{x}$ & $\mathrm{x}$ & $\mathrm{x}$ \\
\hline
\end{tabular}

${ }^{5}$ A better prevention of workplace accidents also brings organisational and social benefits since it should go with a reduction of the costs due to employees' failure.

${ }^{6} \mathrm{~A}$ better health protection for workers also brings organisational and social benefits since it should go with a reduction of the costs due to employees' failure. 


\begin{tabular}{|l|c|c|}
\hline $\begin{array}{l}\text { Opportunity of a reduction of the employer's control regarding his/her employees' Health } \\
\text { (since this control may be delegated to the ubiquitous system) [BOOS et al., 2012]. }\end{array}$ & $\mathrm{x}$ & \\
\hline $\begin{array}{l}\text { Opportunity of a better control of epidemic diseases thanks to early detection, good anticipa- } \\
\text { tion and early treatment of contagious diseases. }\end{array}$ & $\mathrm{x}$ & $\mathrm{x}$ \\
\hline $\begin{array}{l}\text { Opportunity of increasing productivity or the economic and managerial performance of the } \\
\text { organization thanks to the improvement in the workers' health (decrease of absenteeism due } \\
\text { to illnesses and improvement in some abilities such as concentration, dexterity, etc.). }\end{array}$ & $\mathrm{x}$ & $\mathrm{x}$ \\
\hline
\end{tabular}

\begin{tabular}{|c|c|c|c|}
\hline Table 2: Risks and potential drawbacks for the... & ind. & org. & soc. \\
\hline $\begin{array}{l}\text { Risk of invasion of workers' privacy connected to the recording, handling and possible } \\
\text { transmission of data containing personal information about the workers' (physical or psychic) } \\
\text { health or habits which may have a medical impact (ex: inappropriate repetitive movements } \\
\text { which may cause back pain) [SPIEKERMANN et al., 2009]. }\end{array}$ & $\mathrm{x}$ & & \\
\hline Risk of (negative) discrimination of workers because of their health status. & $\mathrm{x}$ & & \\
\hline $\begin{array}{l}\text { Risk of development of inequalities among employees for the access to the benefits offered } \\
\text { by a health monitoring system due to the implementation and management costs of IWEs. }\end{array}$ & $\mathrm{x}$ & & \\
\hline $\begin{array}{l}\text { Risk of infringement of the worker's right not to know (communication to the worker of data } \\
\text { concerning his/her health that he or she does not want to know, such as for instance a form of } \\
\text { cardiac risks [FLORIDI, 2010] }\end{array}$ & $\mathrm{x}$ & & \\
\hline $\begin{array}{l}\text { Risk of development or reinforcement of managerial paternalism, related to the power and } \\
\text { authority conferred by the medical knowledge on workers. [KINDER et al., 2008]. }\end{array}$ & $\mathrm{x}$ & & \\
\hline $\begin{array}{l}\text { Risk of development of inequalities among the organisations in the access to the economic } \\
\text { advantages offered by the IWEs due to the costs requested for their implementation and man- } \\
\text { agement }\end{array}$ & & $\mathrm{x}$ & \\
\hline $\begin{array}{l}\text { Risk of loss of employees' trust in their employer due to a misuse of data containing personal } \\
\text { medical information [HEESEN et al., 2007]. }\end{array}$ & $\mathrm{x}$ & $\mathrm{x}$ & \\
\hline $\begin{array}{l}\text { Risk of transmission of false medical data (to the employee, the employer, etc.) because of } \\
\text { programming errors, data forgery or viruses. }\end{array}$ & $\mathrm{x}$ & $\mathrm{x}$ & \\
\hline $\begin{array}{l}\text { Risk of delegating to the ubiquitous system employees' and employers' responsibility regard- } \\
\text { ing the health in the workplace [BOOS et al., 2012] }\end{array}$ & $\mathrm{x}$ & $\mathrm{x}$ & $\mathrm{x}$ \\
\hline $\begin{array}{l}\text { Risk of employees and employers' loss of control over occupational health (e. g. loss of the } \\
\text { human capacity to detect critical health situations) [TAVANI, } 2011 \text {; BOOS et al., 2012] }\end{array}$ & $\mathrm{x}$ & $\mathrm{x}$ & $\mathrm{x}$ \\
\hline $\begin{array}{l}\text { Risk of an increase in stress due to the knowledge of being potentially observed by the ubiq- } \\
\text { uitous system (cf. extension of the Panopticon logic) [Foucault, 1975]. }\end{array}$ & $\mathrm{x}$ & $\mathrm{x}$ & $\mathrm{x}$ \\
\hline
\end{tabular}

$\begin{array}{ll}\text { Legend: } & \text { ind. }=\text { individual } \\ & \text { org. }=\text { organisation } \\ & \text { soc. }=\text { society }\end{array}$

${ }^{7}$ In his article « Ethics after the Information Revolution », Luciano Floridi [FLORIDI, 2010] shortly points out to a similar risk when he speaks of a « substantial erosion of the right to ignore » (7). 
These two lists are not exhaustive, but are intended to provide a general overview of the potential (positive and negative) impacts of the development of ambient intelligence in the workplace. Furthermore, the distinction that we make between the individual, organizational and social levels should not be taken literally. Such distinctions remain somehow arbitrary and artificial. Indeed, depending on several circumstances, an increase in productivity or a better economic-managerial performance of a company can provide employees with benefits (for example, perks/bonuses). Nevertheless, it seems to me useful to differentiate at which level lie the advantages/disadvantages brought by the development of IWEs.

\subsection{Socio-Anthropological Issues Re- lated to the Underlying Assumptions of IEs}

This consequentialist approach offers the advantage to highlight some of the concrete challenges raised by the development of AmI in the workplace, even if confining ourselves to this kind of approach would lead us to miss more fundamental issues. Without going into the details of the meta-ethical discussion [FLORIDI et al., 2002; TAVANI, 2010; WIEGERLING, 2008], it should be noted that the developments of AmI rely on presuppositions and normative choices that have important socioanthropological implications.

The identification of these presuppositions and choices is far from being self-evident. Their implicit or even unconscious character makes the exercise even more complex. However, reviewing the literature devoted to this matter, it can be stated that the research conducted in the field of AmI is generally based on the presuppositions that 1) the limits and boundaries which define the human being as well as the social structures and relations are not "useful", that 2) these limits restrict the range of our possibilities and, finally, 3) removing them would increase our individual and collective well-being. On the normative level, the equivalent of these presuppositions is that we must do everything in our power to support the removal of all socio-anthropological limits and boundaries.

These objective and normative assumptions (or validity claims, to use HABERMAS' words, 1981) appear in the speeches that accompany the development of ubiquitous computing. The analysis of these speeches shows a trend to consider the blur of boundaries as a value: bridging the gap between humans and machines and developing "seamlessness infrastructures" is seen as undoubted progress which offers obvious pragmatic advantages, notably for users [RATTO 2007]. The result is the current blur of all the traditional boundaries which exists between systems, individuals and organizations. Thus, as Luciano Floridi says:

"We are slowly accepting the idea that we are note standalone and unique entities, but rather informationally embodied organisms (inforgs), mutually connected and embedded in informational environment, the infosphere, which we share with both natural and artificial agents similar to us in many respects" [FLORIDI, 2010, 11].

"ICTs are as much re-ontologizing our world as creating new realities. The threshold between here (analogue, carbon-based, offline) and there (digitial, silicon-based, online) is fast becoming blurred, but this is as much for the advantage of the later as it is to the former. The digital is spilling over into the analogue and merging with it [...]. As a consequence of such re-ontologizing of our ordinary environment, we shall be living in an infosphere that will become increasingly synchronized (time), delocalized (space) and correlate (interactions)" [FLORIDI, 2010, 8-9].

The potential impacts of these evolutions are significant.

1. On the anthropological level first. With the development of ubiquitous computing machines are becoming more and more humanized. In other words, the technological tool gradually acquires the capacity to think and to act like any individual in the social body. As a consequence, it seriously raises the question of its moral status and legal personality. Can we/should we regard a smart system as a being who is potentially responsible (accountable/liable) for its "actions" and "decisions"? [FLORIDI, 2008; HILDEBRANDT, 2008].

At the same time, the human beings are becoming more and more technologically driven: our actions and decisions are increasingly dependent on computers, at the risk of weakening, or even losing, our own competences [SWIFT, 2007]. In other words - and 
getting back to the question at hand -, it may be that by putting the capacity to assess and manage our health status into the hands of the ambient intelligence we are gradually led to call in question or neglect our own capacities in this field. Indeed, as Adam Swift points it out:

"The surrender of a certain degree of agency to ubiquitous computing systems is a trade that should not be taken lightly or without deeper inquiry [...]. When McLuhan argues that every technological 'extension' of human faculties corresponds with an 'amputation', he is suggesting that while our reliance on new technological systems may relieve some of the burdens of everyday life, our organic faculties are likely to - 'atrophy to a corresponding degree"" [SWIFT, 2007, 37].

(2) But that is not all. The developments of AmI also imply a complete reconfiguration of the social functions and spaces. A working environment capable of measuring the employees' physiological data and to meet their needs changes the role and the power of the employer. As briefly mentioned the latter may in the world of ambient intelligence, be authorized - through the knowledge and skills conferred upon it by the machine - to take on a resolutely active role in maintaining the health of his/her employees, in the same way as a doctor or a therapist would. Similarly, we can expect that the role of physicians will also evolve and that they will be requested to contribute to the improvement of the company's performance because of their (medical) knowledge.

Such interferences regarding functions and roles will surely have repercussions on the borders of social spheres. As the firm becomes an area capable of controlling and operating synchronically its coworkers' health, the definition of the area itself is being transformed, and potentially becomes a therapeutic (or para-therapeutic) care center.

How can or should this new field be seen with regard to the care centers that already exist? Furthermore, what will become medical centers and hospitals when AmI's medical skills will be developed and running in our working places?

\section{Discussion}

As the latter section shows it, it becomes clear that social, anthropological, and ethical - both complex and fundamental - matters come into play, and that the answers cannot be let neither to the responsibility of a certain group (IT, HR managers, lawyers, etc.) nor exclusively taken individually.

The stakes related to AmI's development (at work) call upon a shared responsibility. They must thereby be the object of public and wide-ranging discussions (HABERMAS, 1991) designed to validate shared moral values that we want to pursue, and ethical or legal norms that we consider essential regarding the possible perspectives that AmI could offer.

In this perspective, it is urgent not only to spread such researches on the development of AmI technology to a wide public, but also to encourage the debate within companies and in the whole society.

This debate must first be on the merits of the AmI's development. In other words, we should communicate now, publically and with transparency, the underlying assumptions and axiological choices (objective and normative validity claims) of the research, and we should validate or invalidate them in a concerted manner.

We must question ourselves about the boundaries that define our conception of the human being, and social relationships. Are these boundaries still useful or relevant? Should we move them, go past them, reassert them, strengthen them? And in that case, why and for what purpose?

In the meantime, and without any prejudice about the results of this discussion, we have to make sure to anticipate AmI's development, especially in the field of work, and this must be done without any delay. Ubiquitous computing - as almost any other technology - has an important power of attraction and fascination. As seen, it vehicles a lot of promises and offers opportunities we cannot deny: a better professional integration for disabled people, a better safety at work, a better health protection, etc. These elements make us think that there is a fair chance that AmI will continue growing even if we doubt - partially or totally - about the underlying assumptions and axiological choices.

Thereby it is essential that we pursue together the discussion about the possible consequences of AmI's development, and that we continue questioning ourselves about the normative framework that should be built in order to counteract the potential negative effects.

In order to shape the latter subject I would like to 
finish with some ethical principles that I believe could help thwarting these potential negative effects.

As I see it, some conditions must be respected so that the gathering and management of medical information by AmI can be accepted.

\section{Protection of privacy}

Medical data measured in the workplace are properties of employees. The employer (or any other person) may have access to them only if a preponderant good requires it. I am not entitled to tell, on my own, what this preponderant good might exactly be. It must be defined democratically through an open and public discussion. Nevertheless, it seems obvious to me that if a good brings advantages to a restricted part of the population it cannot be considered as preponderant [RAWLS 1971].

1. Protection of privacy over productivity

It seems to me that the productivity of a firm promotes in theory only a certain group of people (mainly managers or shareholders) without creating equality. Thereby productivity cannot be a priori defined as a preponderant good, and does not justify the recording and handling of workers' medical data.

2. Balance between privacy's protection and protection against impoverishment

The case is slightly different if the existence of the company is threatened. From the employee's point of view we may understand that he or she may be willing to renounce to his or her privacy in order to secure his or her existence and the existence of his or her family. But from a political ethical perspective, the infringement of the workers' privacy for the sake of the company survival, or even, for the sake of economical interests is hard to defend. As a society we have the power to set a legal framework which may prevent companies from being economically dependent on the medical information delivered through IWEs. To say it in other words, nowadays companies can survive without these kinds of environments and without storing any special information on their employees' health. Possessing such environments and such information does not constitute a competitive advantage. Yet, this aspect can change in future. If we want to protect privacy, we must assume our political responsibility and prohibit the collection of workers' medical data in order to gain a competitive advantage.

3. Balance between privacy and population's health

A major epidemiologic risk could justify the gathering and handling of a worker's medical data through IWEs. In this case, it will be necessary to take into account the probability as well as the gravity of the risk (degree and speed of contagion, degree of morbidity and mortality, gravity of the disease, existence of preventive and therapeutic means, etc.).

\section{Health protection}

The medical data collected through IWEs should not be harmful to the workers' health. Only some preponderant good may justify health damage.

1. Primacy of the best possible sanitary situation

A major epidemiologic risk could justify the use of IWEs causing health damage. However, in this case, it will be necessary to take into account the probability as well as the gravity of the risk (see above)

2. $\quad$ Primacy of the worker's health over productivity

The improvement in the company's productivity may not be considered as a preponderant good. It does not permit to justify any damage to the workers' health (see above).

\section{Free and informed consent}

Workers must receive complete, comprehensive and transparent information about the data that will be collected at their place of work (nature and extent of the data collected, way they will be used, etc.) before the activation of the AmI system. They must also have the possibility to give their free consent to the collection and the handling of such data (item mentioned in the employment contract for instance). 
IV. Control of the employer's data handling

The way in which data are used by the company must be submitted to regular control by an external institution. Disregard of the legal and ethical rules must be submitted to sanctions.

\section{Protection of the weakest co-workers}

The medical data collected through IWEs must not be used in order to justify managerial measures causing a negative discrimination among workers. Yet, we may accept as legitimate the use of such data in order to improve the working conditions of a person experiencing a physical or psychic deficiency, if this deficiency affects his or her well-being in the company, provided that explicit consent is given by those concerned.

\section{Protection against false data}

Everything must be done in order to guarantee the validity of the (medical) data collected at the workplace, and its protection against forgery and viruses.

\section{Conclusion}

I have tried to show that IWEs and their ability to collect and handle medical data raise fundamental ethical issues. It is important that these stakes can be debated and discussed, not only amongst academics, but also within companies, publicly and politically.
Indeed the first applications of AmI are coming onto the market very rapidly. These applications will have considerable implications on our everyday organization and our conception of human beings and social relations. If we want to take an active and constructive part in these changes it is urgent to begin the discussion now.

\section{References}

[ALLANSON et al., 2004]

[ANISETTI et al., 2006]

[BOHN et al., 2004]

[BOOS et al., 2012]

[BÜHLER, 2009]

[CORCHADO et al., 2008]

[FOUCAULT, 1975]

[FLORIDI, 2010]
ALLANSON, Jennifer, Fairclough, S. H. A Research Agenda for Physiological Computing, Interacting with Computer 16 (2004), pp. 857-878.

ANISETTI, Marco, Bellandi, V., Damiani, E., Beverina, F., Ciceri, M.R., Balzarotti, S. Psychology-Aware Video-Enabled Workplace, in: Ubiquitous Intelligence and Computing: Third International Conference, UIC 2006, Wuhan, China, September 3-6, Springer, Berlin et al., pp. 135-146.

BOHN, John, Coroamă, V., Langheinrich, M., Mattern, F., Rohs, M. Living in a World of Smart Everyday Objects - Social, Economic, and Ethical Implications, Journal of Human and Ecological Risk Assessment 10(5) (2004), pp. 763-786.

BOOS, Daniel, Guenter, H., Grote, G., Kinder, K. Controllable accountabilities: the Internet of Things and its challenges for organisations Behaviour \& Information Technology, 2012, pp. 1-19.

BÜHLER, Christian. Ambient Intelligence in Working Environments, C. Stephanidis, (Ed.), Universal Access in HCI. Intelligent and Ubiquitous Interaction Environments, Part II, 5th International Conference, UAHCI 2009, Springer, Berlin et al., 2009, pp. 143-149.

CORCHADO, Juan M., Bajo, J., de Paz, Y., Tapia, D. I. Intelligent environment for Monitoring Alzheimer Patients, Agent Technology for Health Care. Decision Support Systems 44 (2008), pp. 382-396.

FOUCAULT, Michel, Surveiller et punir. Naissance de la prison, Gallimard, Paris, 1975.

FLORIDI, Luciano. Ethics after the Information Revolution, in: L. FLORIDI (Ed.), 
[HABERMAS, 1981]

[HABERMAS, 1991]

[HEESEN et al., 2007]

[HILDEBREANDT, 2008]

[HILTY et al., 2003]

[HILTY et al., 2004]

[HOFKIRCHNER et al., 2007]

[KAPTEIN et al., 2010]

[KINDER et al., 2008]

[LYYTINEN, 2002]

[NIHHOLT, 2004]

[PATTEN et al., 2005]

[RAMOS et al., 2010]

[RAWLS, 1971]

[RÖCKER, 2009]

[RONZANI, 2009]

[SCHUURMANN et al., 2009]
The Cambridge Handbook of Information and Communication Ethics, Cambridge University Press, Cambridge et al., 2010, pp. 3-19.

HABERMAS, Jürgen, Theorie des Kommunikativen Handelns, Suhrkamp, Frankfurt am Main, 1981.

HABERMAS, Jürgen. Erläuterungen zur Diskursethik, Suhrkamp, Frankfurt am Main, 1991

HEESEN, Jessica, Siemoneit, O. Opportunities for Privacy and Trust in the Development of Ubiquitous Computing, International Review of Information Ethics 8 (12) (2007), pp. 47-52.

HILDEBREANDT, Mireille, Ambient Intelligence, Criminal Liability and Democracy, Crim Law and Philos 2 (2008), pp. 163-180.

HILTY, Lorenz M., Behrendt, S., Binswanger, M., Bruinink, A., Erdmann, L., Fröhlich, J., Köhler, A., Kuster, N., Som, C., Würtenberger, F. Das Vorsorgeprinzip in der Informationsgesellschaft. Auswirkungen des Pervasive Computing auf Gesundheit und Umwelt, TA-Swiss 46, Berne, 2003.

HILTY, Lorenz M., Som, C., Köhler, A. Assessing the Human, Social, and Environmental Risks of Pervasive Computing, Human and Ecological Risk Assessment 10 (5) (2004), pp. 853-874.

HOFKIRCHNER, Wolfgang, Tscheligi, M., Bichler R., Reitberger, W. Ambient Persuasion for the Good Society. International Review of Information Ethics 8 (12) (2007), pp. 42-46.

KAPTEIN, Maurits Clemens, Markopoulos, P., de Ruyter, B., Aarts, E. Persuasion in Ambient Intelligence, Journal of Ambient Intelligence and Humanized Computing 1(1) (2010), pp. 43-56.

KINDER, Katharina E., Ball, L. J., Busby, J. S. Ubiquitous Computing, Cultural Logics and Paternalism in Industrial Workplaces, Poiesis Prax 5 (2008), pp. 265290.

LYYTINEN, Kalle, Yoo, Y. Issues and Challenges in Ubiquitous Computing, Communications of the ACM 45(12) (2002), pp. 63-65.

NIHHOLT, Anton. Where Computers Disappear, Virtual Humans Appear, Computers \& Grafics 28 (2004), pp. 467-476.

PATTEN, Karen, Passerini, K. From Personal Area Network to Ubiquitous Computing: Preparing from a Paradigm Shift in the Workplace, in: Wireless Telecommunications Symposium, Institute of Electrical and Electronics Engineers, 2005, pp. 225-233.

RAMOS, Carlos, Marreiros, G., Santos, R., Freitas, C. F. Smart Offices and Intelligent Decision Rooms, in: H. Nakashima, H. Aghajan, J. C. Augusto (Eds.), Handbook of Ambient Intelligence and Smart Environments, Springer Science+Business Media, Berlin, 2010, pp. 851-880.

RAWLS, John. A Theory of Justice. The Belknap Press of the Harvard University Press, Cambridge (Mass.), 1971.

RÖCKER, Carsten. Acceptance of Future Workplace Systems: How the Social Situation Influence the Usage Intention of Ambient Intelligence Technologies in Work Environments, Proceeding of the 9th International Conference on Work with Computer System (WWCS 09), August 9-14, Beijing, China, CD-ROM, 7 pages.

RONZANI Daniel. The Battle of Concepts: Ubiquitous Computing, Pervasive Computing and Ambient Intelligence in Mass Media, UbiCC Journal 4 (2) (2009), pp. 9-19.

SCHUURMANN, Jan Gerrit, Moelaert, F., Krom, A., Walhout, B., Ambient In- 
[SOUSA, 2010]

[SPIEKERMANN et al., 2009]

[STEFANI et al. 2007]

[SWIFT, 2007]

[TAVANI, 2011]

[van den BROEK et al., 2006]

[WEISER et al., 1999]

[WIEGERLING, 2008] telligence. Viable Future or Dangerous Illusion?, Rathenau Instituut, The Hague, 2009.

SOUSA, João Pedro. Foundations of Team Computing. Enabling End Users to Assemble Software for Ubiquitous Computing, in: Complex, Intelligent and Software Intensive Systems. 10 Proceedings of the 2010 International Conference on Complex, Intelligent and Software Intensive Systems, Institute of Electrical and Electronics Engineers Computer Society, Washington DC, 2010, pp. 9-16.

SPIEKERMANN, Sarah, Langheinrich, M. An Update on Privacy in Ubiquitous Computing, Personal and Ubiquitous Computing 13, 2009, pp. 389-390.

STEFANI Oliver, Mager R., Bekiaris E.s, Gemou M., Bullinger A. Merging of Next Generation VR and Ambient Intelligence - From Retrospective to Prospective User Interfaces, in: C. Stephanidis (Ed.), Universal Access in HCI, Part II, Springer, Berlin et al., 2007, pp. 709-714.

SWIFT, Adam, Locating 'Agency' Within Ubiquitous computing Systems, International Review of Information Ethics 8 (12) (2007), pp. 36-41.

TAVANI, Herman. Ethical Aspects of Emerging and Converging Technologies, in: Ethics and Technology. Controversies, Questions, and Strategies for Ethical Computing, John Wiley \& Sons, Hoboken (NJ), 2011, pp. 261-392.

van den BROEK Egon L., Schut, M. H., Tuinenbreijer, K. Joyce H.D.M. Westerink, J. H. D. M. Communication and Persuasion Technology: Psychophysiology of Emotions and User-Profiling, in: Persuasive Technology, Lecture Notes in Computer Science 3962, Springer, Berlin et al., 2006, pp. 154-157.

WEISER, Mark, Gold, R., Seely Brown, J. The Origins of Ubiquitous Computing Research at PARC in the Late 1980s, IBM System Journal 38(4) (1999), pp. 693696.

WIEGERLING, Klaus. The Two Basic Questions of Ethics and the Loss of the Interface in Ambient Intelligence, in: W. Hesse, A. Oberweis (Eds.), SIGSANDEUROPE 2008, Proceedings of the Third AIS SIGSAND European Symposium on Analysis, Design, Use and Societal Impact of Information Systems, June 12 13, 2008, Marburg, pp. 1-20. 